\title{
Penerapan Ipteks untuk Pengembangan Potensi Limbah Tempurung sebagai Upaya Peningkatan Pendapatan Masyarakat
}

Muhammad Bukhori Dalimunthe1, Rosmala Dewi², Muhammad Andi Abdillah Triono²,

Dirga Purnama², Hendri², Fitri Yani Panggabean ${ }^{3}$

1, 2 Universitas Negeri Medan, ${ }^{3}$ Universitas Pembangunan Pancabudi

\begin{tabular}{|c|c|}
\hline Article History & ABSTRACT \\
\hline $\begin{array}{l}\text { Received 17.01.2019 } \\
\text { Received in revised form } \\
08.04 .2019 \\
\text { Accepted } 26.07 .2019 \\
\text { Available online } 20.08 .2019\end{array}$ & $\begin{array}{l}\text { IMPLEMENTATION OF SCIENCE AND TECHNOLOGY FOR THE DEVELOPMENT } \\
\text { OF COCONUT SHELL WASTE AS AN EFFORT TO INCREASE COMMUNITY } \\
\text { INCOME. The problems that occur in the community of Sei Paham Village are not yet } \\
\text { optimal use of coconut, which is one of the largest coconut production villages in Sei } \\
\text { Kepayang District. It requires the acquisition of science and technology in maximizing } \\
\text { coconut shell waste into charcoal. The purpose of the service is to implement science } \\
\text { and technology in processing coconut shell waste into charcoal as an effort to increase } \\
\text { the income of the people of Sei Paham Village. The community empowerment method } \\
\text { uses participatory learning and action to be very useful in increasing knowledge and } \\
\text { skills by involving community participation in several ways, including: (1) analysis of } \\
\text { the situation of potential derivative products from coconut waste; (2) able to design the } \\
\text { charcoal combustion devices that have been produced with the service team; and (3) } \\
\text { skilled in quality charcoal production. The results of dedication are seen in increasing } \\
\text { income and skills in utilizing shell waste. The application of science and technology in } \\
\text { developing the potential of shell waste also has a positive impact on the surrounding } \\
\text { environment, this is there is no longer a coconut shell buildup because the community } \\
\text { has been able to optimize the shell using a coconut shell combustion device to become } \\
\text { charcoal. KEYWORDS: Coconut Shell Waste, Community Income, Participatory } \\
\text { Learning. }\end{array}$ \\
\hline
\end{tabular}

KEYWORDS: Coconut Shell Waste, Community Income, Participatory Learning.

\section{PENDAHULUAN}

Desa Sei Paham merupakan salah satu desa yang terdapat di Kecamatan Sei Kepayang, Kabupaten Asahan, Provinsi Sumatera Utara, yang merupakan mitra Program Pengembangan Desa Mitra (PPDM) yang terdiri dari masyarakat Desa Sei Paham yang

${ }^{1}$ Corresponding author: Program Studi Pendidikan Ekonomi, FE Universitas Negeri Medan; Jl. Willem Iskandar Pasar V, Medan, Sumatera Utara, Indonesia; Email: daliori86@unimed.ac.id 
berperan sebagai pemilik maupun buruh pada perkebunan kelapa masyarakat. Kabupaten Asahan sebagian besar daerahnya merupakan lahan perkebunan kelapa sawit, karet, coklat, dan kelapa yang merupakan salah satu sentra perkebunan di Provinsi Sumatera Utara. Pada tahun 2017, produksi kelapa sawit (tandan buah segar) sebesar 1.595.126,63 ton yang menjadikan Kabupaten Asahan sebagai pusat perkebunan kelapa sawit rakyat di Sumatera Utara, produksi karet sebesar 5.405,95 ton, produksi coklat sebesar 610,38 ton, dan produksi kelapa sebesar 22.486,42 ton dengan luas tanaman mencapai 22.059,62 ha dimana Kecamatan Sei Kepayang, Silau Laut, dan Tanjung Balai merupakan penghasil kelapa di Kabupaten Asahan (BPS Asahan Dalam Angka, 2018).

Besarnya kapasitas produksi kelapa yang dihasilkan Kecamatan Sei Kepayang di dominasi oleh Desa Sei Paham yang merupakan desa terbesar penghasil kelapa di Kecamatan Sei Kepayang (BPS Sei Kepayang Dalam Angka, 2018), tetapi belum dimaksimalkan oleh masyarakat dalam mengelola kelapa. Masyarakat belum optimal memanfaatkan potensi kelapa, mereka hanya memanfaatkan kopra (daging kelapa) untuk dijual kepada pengumpul. Sedangkan tempurung, sabut, dan air kelapa belum dimanfaatkan menjadi barang yang memiliki nilai ekonomis. Panggabean dkk (2018) menjelaskan potensi pengolahan limbah kelapa berupa tempurung, dapat meningkatkan nilai tambah kelapa dalam upaya peningkatan kesejahteraan.
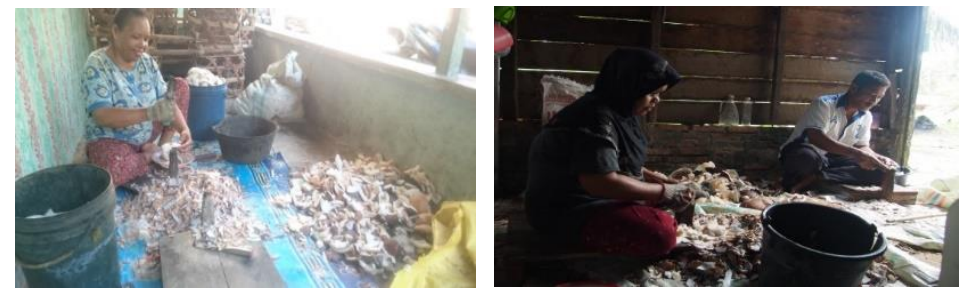

Gambar 1. Aktivitas Masyarakat Mengolah Kelapa Menjadi Kopra

Beberapa petani kelapa memanfaatkan limbah tempurung kelapa menjadi arang. Dalam proses pembuatan arang tersebut masih secara konvensional, yaitu dengan cara membakar tempurung ditanah atau lahan petani kelapa kemudian memadamkan bara tempurung tersebut dengan menggunakan air, sehingga arang yang dihasilkan memiliki kualitas yang rendah karena mengandung kadar air yang tinggi dan telah tercampur dengan tanah.

Tabel 1. Persentase Penduduk Menurut Golongan Pengeluaran Perkapita Sebulan Kab. Asahan, 2017

\begin{tabular}{ll}
\hline Golongan Pengeluaran Perkapita Sebulan (Rp) & Persentase Penduduk \\
\hline$<200.000$ & 0,23 \\
$200.000-299.999$ & 2,45 \\
$300.000-499.999$ & 30,63 \\
$500.000-749.999$ & 36,97 \\
$750.000-999.999$ & 15,30 \\
$1.000 .000-1.249 .999$ & 6,81 \\
$1.250 .000-1.499 .999$ & 3,46 \\
$\geq 1.500 .000$ & 4,15 \\
\hline Jumlah & 100,00 \\
\hline \multicolumn{2}{c}{ Sumber: BPS Kabupaten Asahan Dalam Angka, 2018 }
\end{tabular}


Saat ini, masyarakat pemilik kebun kelapa menjual kelapa dalam dua bentuk yaitu kelapa bulat dengan harga Rp. 3.000/kg dan kopra seharga Rp. 8.000/kg. Begitu juga pemanfaatan limbah tempurung kelapa menjadi arang saat ini dijual petani seharga $\mathrm{Rp}$. 3.000/kg dengan kualitas rendah karena kadar air yang tinggi. Tentu saja harga ini masih sangat rendah untuk memenuhi pengeluaran konsumsi masyarakat. Data statistik menunjukkan pengeluaran per kapita sebulan masyarakat Kabupatan Asahan di dominasi rentang Rp. 500.000 sampai Rp. 750.000 sebesar 36,97\% (lihat Tabel 1).

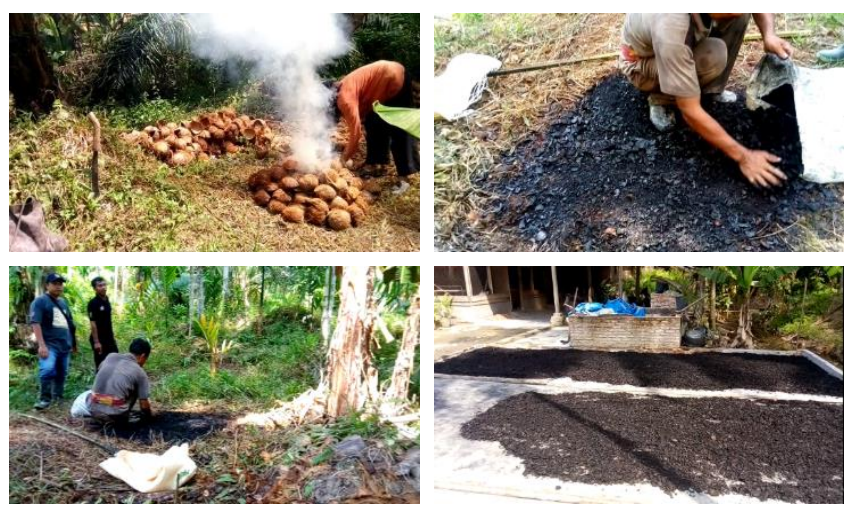

Gambar 2. Aktivitas Masyarakat Mengolah Tempurung Menjadi Arang Secara Konvensional

Rendahnya pengeluaran perkapita masyarakat, mengindikasikan bahwa pendapatan yang diperoleh masyarakat juga rendah. Hal ini berbanding terbalik dengan potensi sumber daya kelapa yang terdapat di Desa Sei Paham. Belum optimalnya pemanfaatan produksi turunan buah kelapa merupakan salah satu penyebab rendahnya penghasilan masyarakat. Permasalahan umum yang terjadi pada petani kelapa dalam pengelolaan hasil produksi diantaranya terbatasnya pengetahuan, teknologi tepat guna, dan manajemen usaha (Ane dan Dalimunthe, 2015). Melalui kegiatan PPDM, akan dirancang serangkaian kegiatan pengabdian yang bertujuan menerapkan ipteks dalam pengolahan limbah tempurung kelapa menjadi arang sebagai upaya peningkatan pendapatan masyarakat Desa Sei Paham.

\section{METODE PELAKSANAAN}

Pengabdian dilaksanakan pada kelompok petani kelapa Desa Sei Paham Kecamatan Sei Kepayang Kabupaten Asahan yang berjarak \pm 195 kilometer atau sekitar 4 jam perjalanan darat dari Universitas Negeri Medan. Kegiatan program pengembangan desa mitra yang dilakukan oleh tim pengabdi merupakan salah satu upaya untuk menerapkan hasil-hasil riset perguruan tinggi kepada masyarakat. Metode pelaksanaan pemberdayaan masyarakat menggunakan Participatory Learning and Action (PLA) merupakan metode pemberdayaan dengan melibatkan masyarakat yang terdiri dari proses belajar sambil bekerja (Ibnouf dkk, 2015) untuk pengolahan limbah tempurung kelapa menjadi arang dengan pemadaman pembakaran tempurung tanpa menggunakan air, melainkan penerapan teknologi tepat guna hampa udara sehingga arang yang dihasilkan dengan kadar air yang sangat rendah. Tahapan kegiatan pengabdian yang dilakukan dengan metode PLA, sebagai berikut:

1) Analisis situasi, pada tahap ini tim pengabdi menguraikan potensi, nilai strategis, kondisi sosial dan ekonomi, serta permasalahan Desa Sei Paham berdasarkan data dan 
informasi dari Kepala Desa, kelompok petani kelapa, dan Badan Pusat Statistik Kabupaten Asahan. Diperlukan partisipasi Kepala Desa Sei Paham dan kelompok petani kelapa untuk dapat secara terbuka memberikan informasi guna penentuan root of problem yang dihadapi.

2) Rancang bangun alat pembakaran tempurung, pada tahap ini tim pengabdi melakukan transfer knowledge ipteks perguruan tinggi kepada kelompok petani kelapa untuk bersama-sama melakukan rancang bangun agar alat tersebut dapat disesuaikan dengan kebutuhan masyarakat untuk memanfaatkan limbah tempurung kelapa.

Pelatihan produksi arang, pada tahap ini tim pengabdi melakukan pelatihan produksi dengan menggunakan alat pembakaran tempurung untuk meningkatkan pendapatan masyarakat dengan memanfaatkan limbah tempurung kelapa.

\section{HASIL DAN PEMBAHASAN}

Kegiatan program pengembangan desa mitra bertujuan untuk mengejawantahkan hilirisasi hasil riset perguruan tinggi guna membangun Desa Sei Paham. Berdasarkan tujuan tersebut diperoleh kebermanfaatan bersama, dimana perguruan tinggi akan memperoleh income generate dan pemerintah desa akan memperoleh peningkatan kesejahteraan masyarakat. Dewi dan Dalimunthe (2017) menjelaskan perlu adanya unit bisnis yang dikelola oleh dosen dan mahasiswa sebagai income generate serta wadah pelayanan kepada masyarakat.

Peningkatan kesejahteraan masyarakat melalui pemanfaatan potensi limbah tempurung kelapa yang dilakukan oleh tim pengabdi bersama kelompok petani kelapa Desa Sei Paham telah menunjukkan adanya peningkatan pendapatan dan keterampilan masyarakat. Peningkatan yang diperoleh tentu saja melalui beberapa tahapan kegiatan yang melibatkan partisipasi kelompok petani.

\section{Focus Group Discussion Analisis Situasi Potensi Desa Sei Paham}

Focus Group Discussion (FGD) merupakan bentuk kegiatan pengumpulan data melalui wawancara kelompok dan pembahasan terarah dalam menyelesaikan permasalahan. FGD yang dilakukan bertujuan untuk memberikan informasi kepada kelompok petani kelapa dan masyarakat lainnya tentang potensi, nilai strategis, kondisi sosial dan ekonomi yang terdapat di Desa Sei Paham. Kegiatan FGD dihadiri oleh kelompok petani kelapa, kepala dusun, dan Kepala Urusan Perencanaan Pemerintah Desa Sei Paham. FGD dilakukan pada tanggal 09 Mei 2018 di Kantor Desa Sei Paham Kecamatan Sei Kepayang Kabupaten Asahan. Kegiatan FGD menghasilkan permasalahan prioritas yang terletak pada root of problem yang dialami kelompok petani kelapa yang akan diselesaikan secara bersama tim pengabdi. Adapun root of problem kelompok petani kelapa, antara lain:

1) Kelompok petani kelapa belum memiliki pengetahuan dan keterampilan dalam memanfaatkan limbah tempurung kelapa secara maksimal.

2) Pendapatan masyarakat Desa Sei Paham yang masih rendah. Kelompok petani kelapa saat ini bekerja sebagai petani dan buruh tani memanfaatkan daging kelapa untuk membuat kopra dan tempurung kelapa untuk membuat arang dengan harga jual yang rendah. 
3) Tengkulak memanfaatkan permasalahan ekonomi kelompok petani kelapa Desa Sei Paham. Tengkulak mengatur mekanisme pasar dan harga kelapa.

4) Kelompok tani yang terdapat di Desa Sei Paham masih banyak yang belum memiliki status badan hukum. Dari jumlah 16 kelompok tani yang sudah memiliki badan hukum berjumlah 2 kelompok tani, sedangkan sisanya hanya memperoleh sertifikat pengukuhan kelompok tani dari Camat Sei Kepayang.

5) Belum optimalnya BUMDes Desa Sei Paham, dikarenakan lemahnya pengetahuan dan keterampilan perangkan desa dalam mengelola BUMDes.

Berdasarkan root of problem yang telah dijabarkan, maka disusun beberapa rencana kegiatan telah disepakati bersama oleh tim pengabdi, kelompok petani kelapa, dan Pemerintah Desa Sei Paham untuk mengatasi root of problem kelompok petani kelapa disajikan pada Tabel 2.

Tabel 2. Hasil Kesepakatan Focus Group Discussion Pelaksanaan PPDM

\begin{tabular}{lll}
\hline Kegiatan & Target Luaran & \\
\hline FGD analisis situasi potensi Desa Sei Paham & $\begin{array}{l}\text { Informasi potensi, kondisi } \\
\text { ekonomi dan sosial }\end{array}$ & \\
& 1 unit mesin & \\
Membuat mesin arang kelapa & Arang \\
Peningkatan kuantitas dan kualitas produk mitra & 1 unit mesin produksi & \\
Penyerahan mesin produksi &
\end{tabular}

\section{Rancang Bangun Alat Pembakaran Tempurung}

Kegiatan pengabdian selanjutnya mengembangkan potensi Desa Sei Paham dengan penerapan ipteks melalui rancang bangun alat pembakaran tempurung (selanjutnya disebut sebagai BARA). Rancang bangun alat BARA dirancang semaksimal mungkin untuk menghasilkan arang tempurung dengan kualitas yang baik. Alat BARA dirancang oleh Dosen Fakultas Teknik dan Ekonomi Universitas Negeri Medan dari informasi kesulitan-kesulitan yang dialami oleh kelompok petani kelapa dalam membakar tempurung. Perancangan alat BARA dimulai dari menggambar alat serta spesifikasinya, uji coba, dan simulasi sehingga diperoleh alat BARA yang sesuai dengan kebutuhan kelompok petani kelapa. Adapun rancangan alat BARA dapat dilihat pada Gambar 3, Gambar 4, Gambar 5.

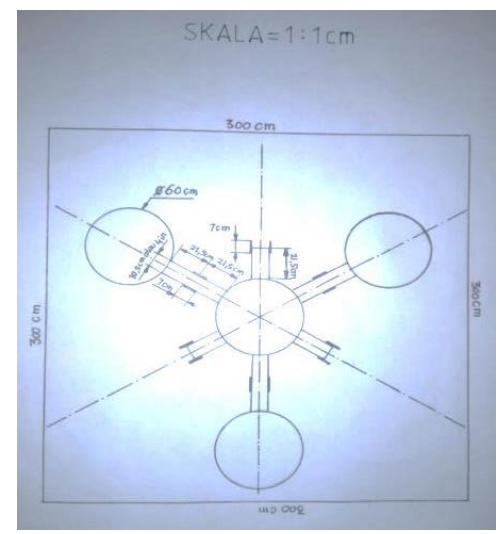

Gambar 3. Blueprint Rancang Bangun Alat BARA 


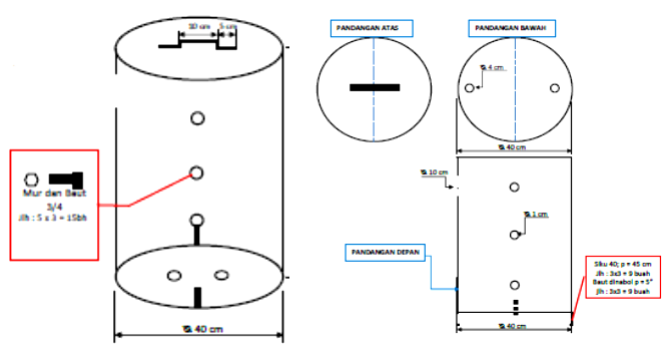

Gambar 4. Blueprint Drum (Tong Besi) Pembakaran Tempurung
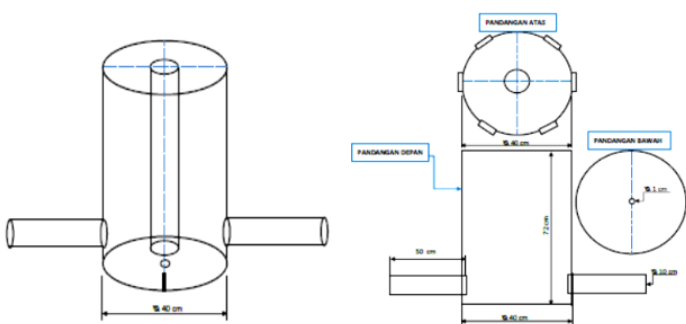

Gambar 5. Blueprint Drum Pengendap Asap

Alat BARA dibuat dari bahan baku 4 (empat) buah drum, dimana 3 (tiga) buah drum sebagai pembakaran tempurung dan 1 (satu) tong sebagai pengendap asap sehingga asap yang dihasilkan dari pembakaran tempurung dapat diminimalisir. Alat BARA telah melalui berbagai uji coba dan simulasi pembakaran tempurung agar diperoleh tempurung dengan kualitas yang baik. Tempurung dibakar menggunakan drum pembakaran yang telah diberikan lubang angin yang bertujuan untuk mengontrol udara masuk dan keluar pada saat pembakaran. Kemudian asap dari drum pembakaran diarahkan melalui pipa besi ke drum pengendap asap yang telah disambungkan dengan corong asap yang terbuat dari pipa besi sepanjang 10 meter agar asap pembakaran tidak mengganggu warga sekitar produksi pembakaran tempurung. Setelah tempurung terbakar menjadi arang, maka semua lubang angin yang terdapat pada drum pembakaran ditutup rapat agar api padam karena hampa udara sehingga dihasilkan arang dengan kualitas yang baik.

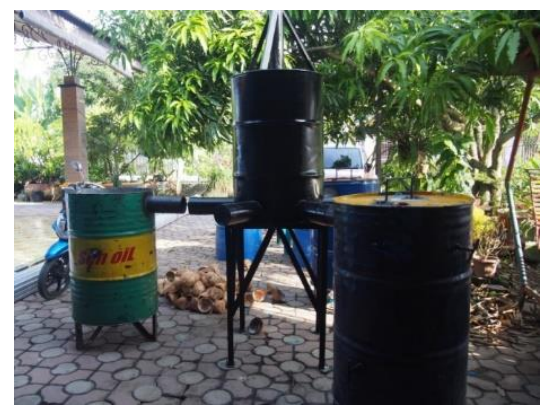

Gambar 6. Alat BARA

\section{Pelatihan Produksi Arang}

Pelatihan produksi arang menggunakan alat BARA merupakan teknologi tepat guna menggantikan cara konvensional yang selama ini dilakukan oleh kelompok petani kelapa Desa Sei Paham. Arang yang dihasilkan dengan metode konvensional dengan cara dibakar ditanah atau lahan kemudian dipadamkan arang tersebut dengan api sehingga 
kualitas arang menjadi tidak baik menyebabkan harga jual arang sangat rendah sebesar Rp. $2.000 / \mathrm{kg}$.

Pembakaran tempurung menggunakan alat BARA dibakar menggunakan drum, kemudian dirancang drum pengendali asap sehingga asap yang dihasilkan dari pembakaran diarahkan ke drum pengendali asap yang menyebabkan terjadinya proses menyublin dari asap menjadi cair, sehingga asap menjadi lebih sedikit serta tidak menggangu masyarakat sekitar. Begitu juga pada saat pemadaman api pembakaran tempurung menggunakan hampa udara, dimana semua lubang angin yang terdapat pada drum pembakaran ditutup rapat agar tidak masuk udara sehingga api padam. Pembakaran arang dengan menggunakan alat BARA menghasilkan arang yang berkualitas dengan harga Rp.8.000/kg. Setelah pelatihan produksi arang berakhir, tim pengabdi menyerahkan 1 (satu) unit alat BARA kepada kelompok petani kelapa Desa Sei Paham untuk dipergunakan sebagai alat produksi arang.

Pada bulan Oktober, kelompok petani kelapa sudah mulai melakukan produksi arang dari tempurung kelapa dengan menggunakan alat BARA. Pembakaran arang dilakukan dengan kapasitas $56 \mathrm{~kg}$ tempurung dengan menggunakan 1 drum pembakaran. Pembakaran tempurung dilakukan selama 6 jam menghasilkan $\pm 17 \mathrm{~kg}$ arang yang siap dijual. Produksi pembakaran arang sampai akhir bulan Oktober dengan total produksi arang sebanyak $150 \mathrm{~kg}$, kemudian dijual ke pabrik yang berada di daerah Kabupaten Asahan dengan harga Rp. 8.000/kg. Taksiran perhitungan penjualan arang disajikan pada Tabel 3.

Tabel 3. Taksiran Laporan Produksi Penjualan Arang (Oktober 2018)

\begin{tabular}{lll}
\hline $\begin{array}{l}\text { Produksi arang (berat arang 30\% } \\
\text { dari tempurung) }\end{array}$ & $\begin{array}{l}30 \% \text { dari berat tempurung } \\
(500 \mathrm{~kg} \times 30 \%)\end{array}$ & $150 \mathrm{~kg}$ arang \\
\hline Penjualan & $\mathrm{Rp} .8 .000 / \mathrm{kg} \times 150 \mathrm{~kg}$ & $\mathrm{Rp} .1 .200 .000$ \\
\hline Bahan baku tempurung & $\mathrm{Rp} .1 .000 / \mathrm{kg} \times 500 \mathrm{~kg}$ & $(\mathrm{Rp} .500 .000)$ \\
\hline $\begin{array}{l}\text { Keuntungan } \\
\text { (kapasitas 500kg tempurung) }\end{array}$ & & $\mathrm{Rp.} 700.000$ \\
\hline
\end{tabular}

Serangkaian aktivitas yang telah dilakukan memberikan dampak positif kepada kelompok petani kelapa Desa Sei Paham dalam meningkatkan pendapatan. Pemanfaatan limbah tempurung kelapa dengan kapasitas $500 \mathrm{~kg}$ tempurung dapat menghasilkan tambahan pendapatan sebesar Rp. 700.000. Pengetahuan dan keterampilan kelompok petani kelapa dalam membuat arang terjadi migrasi dari cara konvensional ke teknologi tepat guna yang menyebabkan terjadi perubahan pola pikir dan tindakan kelompok petani kelapa dalam mengelola potensi limbah tempurung kelapa. Perubahan pola pikir dan tindakan mengakibatkan pemanfaatan limbah tempurung kelapa secara optimal dan benar. Tempurung kelapa yang selama ini menjadi limbah berubah menjadi peluang bisnis baru bagi masyarakat Desa Sei Paham.

\section{SIMPULAN}

Berdasarkan kegiatan yang telah dilakukan, maka diperoleh berbagai simpulan program pengembangan desa mitra, antara lain 1) tim pengabdi bersama mitra melakukan focus group discussion yang bertujuan untuk analisis situasi permasalah utama 
dalam mengembangkan potensi desa; 2) tim pengabdi melakukan rancang bangun teknologi sederhana tepat guna berupa alat BARA yang dipergunakan untuk pembakaran tempurung; 3) kelompok petani kelapa memperoleh pengetahuan dan keterampilan pemanfaatan tempurung kelapa menjadi arang yang memiliki kualitas dan nilai ekonomis, sehingga dapat meningkatkan pendapatan; 4) peningkatan daya saing produk mitra berupa arang dengan kualitas baik yang rendah kadar air. Beberapa saran yang dapat diberikan dari kegiatan pengabdian untuk percepatan pengembangan desa, diantaranya; 1) kegiatan produksi arang dapat secara berkelanjutan terus dilakukan oleh kelompok petani kelapa Desa Sei Paham agar dapat menjadi pilot project untuk kelompok petani di desa-desa lain pada Kecamatan Sei Kepayang; 2) Pemerintah Desa Sei Paham dapat memberikan kemudahan akses transportasi dan regulasi untuk mengembangkan kelompok petani kelapa dan masyarakat khususnya Desa Sei Paham;3) diperlukannya pengembangan dan pembinaan mitra melalui Triangulasi dengan melibatkan akademisi, pemerintah, dan pengusaha; dan 4) diperlukannya pembinaan berkelanjutan oleh perguruan tinggi, dengan cara kerja sama sebagai UKM binaan perguruan tinggi agar dapat menerapkan hilirisasi hasil riset perguruan tinggi untuk pengembangan pengetahuan dan keterampilan kelompok petani kelapa dalam mengembangkan

\section{UCAPAN TERIMA KASIH}

Tim pengabdi mengucapkan terima kasih atas kepercayaan Direktorat Riset dan Pengabdian Masyarakat Kementerian Riset, Teknologi, dan Pendidikan Tinggi yang telah memberikan bantuan dana hibah Program Pengembangan Desa Mitra tahun 2018.

\section{REFERENSI}

Ane, L., \& Dalimunthe, M. B. (2015). Ipteks Bagi Masyarakat kelompok usaha petani kelapa desa Sei Paham. Jurnal Pengabdian Kepada Masyarakat, 21(79), 57-64.

Badan Pusat Statistik [BPS] Kabupaten Asahan. (2018). Asahan dalam angka. Asahan: BPS Kabupaten Asahan.

Dewi, R., \& Dalimunthe, M. B. (2017). Peningkatan income generate melalui unit usaha counceling centre berbasis intelektual kampus. Jurnal Pengabdian Kepada Masyarakat, 23(2), 287-291.

Ibnouf, M., Sheqwarah, M., \& Sultan, K. (2015). An evaluation of the participatory learning and action (PLA) training workshop. Journal of Agricultural Science, 7(12), 144-150.

Panggabean, F. Y., Dalimunthe, M. B., \& Suharianto, J. (2018). Peningkatan pendapatan masyarakat Desa Sei Kepayang Tengah melalui pemanfaatan limbah tempurung kelapa. Widya Laksana, 7(1), 18-25. 